\title{
Comparison of physicochemical characteristics and composition of bergamot oil seed extracted from three different cultivars
}

\author{
Vincenzo Sicari, Francesco Messina, Teresa M. Pellicanò \\ Department of AGRARIA, University of Reggio Calabria, Salita Melissari 89124 Reggio Calabria (Italy)
}

\section{A B S T R A C T}

\begin{abstract}
The influence of cultivar on the composition of bergamot seed oil from three cultivars (Castagnaro, Femminello and Fantastico) grown in province of Reggio Calabria (Southern Italy) was investigated. The maximum oil yield was $35.01 \mathrm{~g} / 100 \mathrm{~g}$ in Castagnaro cultivar. The acidity values of the oil varied between 0.62 and $0.87 \mathrm{mg} \mathrm{NaOH}$ per $\mathrm{g}$ of oil, and peroxide values varied between $11.67 \mathrm{meq} / \mathrm{kg}$ and $14.30 \mathrm{meq} / \mathrm{kg}$. Oleic acid was the principle fatty acid found in the extracted oils (31\% to $34 \%)$, followed by linoleic (27\% to $30 \%)$ and palmitic $(21 \%$ to $23 \%)$. Other acids were found in smaller quantities, for example stearic, arachidic and linolenic. $\beta$-sitosterol was the principle sterol that made up over $70 \%$ of total sterols. Other sterols, campesterol, stigmasterol, $\Delta^{5}$-avenasterol, cholesterol and 2,4-methylencolesterol were detected in the majority of the oils. The results of this study showed that the bergamot seeds and the extracted oils have the potential of being used as a source of edible oil.
\end{abstract}

Keywords: Citrus bergamia; Seeds; Oil composition; Fatty acid; Sterol

\section{INTRODUCTION}

All plant seeds contain an oily component to a varying percentage, however, only a few of these are industrially exploited for food: In particular, are used soya, peanut, sunflower, rapeseed, colza, cotton, palm, olive, coconut and grape seed. In recent years vegetable oils have assumed an important role, not only for human consumption, but also in the cosmetics sector (e.g., wheat germ oil, avocado oil) and other industries (chemical, alimentary and pharmaceutical industries) (Rewolinski, 1985; Bhatia et al., 1990; Agbo et al., 1992; Foidl, 1996; Mahmud et al., 2006; Danby et al., 2013; Adiletta et al., 2015; Giuffrè et al., 2015 A; Giuffrè et al., 2015 B; Giuffrè et al., 2015 C; Giuffrè et al., 2016; Sicari and Poiana, 2016).

Not all vegetable oils have the same chemical-physical characteristics, so a thorough study of their composition, is needed to determine how best they can be marketed.

Seed oils are recommended for those at risk of cardiovascular problems, because they can protect against thrombosis, atherosclerosis and heart attack.
The differences between the various types of vegetable oils mainly concerns the fatty acid composition. Most vegetable oils contain mainly mono and polyunsaturated fats and are low in saturated fat. The composition of seed oil fatty acids not only varies from species to species, but also depends on the climatic conditions and the type of soil.

In the processing of citrus fruit, the seeds are considered production waste. Although they make up a minimal part $(3-5 \%)$ of the fruits total weight, they contain an oily fraction which could be exploited for different uses.

Bergamot "Citrus bergamia Risso", is a citrus fruit of the family Rutaceae, of the genus Citrus.

Bergamot, is mostly grown in the province of Reggio Calabria in Italy. Three cultivars exist in Calabria: Castagnaro, Femminello and Fantastico. Today the Fantastico cultivar makes up $90 \%$ of all trees (Dugo et al., 1987). Bergamot has several uses. The peel is used for the production of jam and also in health applications.

\footnotetext{
*Corresponding author:

Vincenzo Sicari, Department of AGRARIA, University of Reggio Calabria, Salita Melissari 89124 Reggio Calabria (Italy).

Tel.: +39 09651694370, E-mail: Vincenzo.sicari@unirc.it
} 
The essential oil is used in the fragrance industry (Ricci and Rovesti 1979; Poiana et al., 1994). The bitter taste of makes it largely unsuitable for use in bergamot juice in the food industry. Citrus seed oil presents chemical and physical characteristics that make it suitable for food consumption (Ramadan and Morsel 2002). In the scientific papers, we find numerous research that have dealt with the oil of citrus seeds. The majority of the research concerns the quantitative analysis of fatty acids (French, 1962; Habib et al., 1986; Saidani et al., 2004; Anwar et al., 2008).

The quality of a food grade oil depends on its fatty acid profile and above all on the ratio of saturated to unsaturated fatty acids.

Furthermore, unsaturated acids can be classed as omega, $\omega-9$, which are considered nonessential, and $\omega-3$ and $\omega-6$, known as essential fatty acids, since they cannot be synthesized by the human body, and must be obtained from diet (Ristic and Ristic 2003). Linoleic acid is present in all vegetable oils and is abundant in many of these, including in sunflower seeds, but also, to a lesser extent, corn oil, soybean oil and others. Linoleic acid an essential fatty acid and belongs to the $\omega-6$ group.

The seeds of the bergamot fruit, which are currently considered a waste material, may not only be a reliable source of edible oil (cooking oil, salad or for margarine) but since it is a semi-drying oil it could also have industrial uses. In this study were evaluated the chemical-physical composition of bergamot oil seed extracted from three different cultivars, in order to evaluate any differences in their composition.

\section{MATERIALS AND METHODS}

\section{Chemicals}

Petroleum ether $\left(40-60{ }^{\circ} \mathrm{C}\right)$ was of analytical grade $<98 \%$, Merck (Milan, Italy). Authentic standard samples of FAMEs, were from Sigma-Aldrich (Milan, Italy). $\beta$-sitosterol, campesterol, and stigmasterol were obtained from Aldrich (Milan, Italy). All other reagents of analytical grade were from Carlo Erba Reagenti (Milan, Italy).

\section{Sampling}

During the 2015/16 season, the Bergamot Consortium of Reggio Calabria (Italy) provided the seeds used. The seeds belonged three different cultivars (Castagnaro, Femminello and Fantastico), formerly, Femminello and Castagnaro made up virtually all commercial plantings but they have largely been replaced by Fantastico, a hybrid of Femminello and Castagnaro.
All the fruit was picked on the same day and processed within 48 hours; the seeds were subsequently divided according to cultivar.

After being washed with tap water, the seeds were dried at $35^{\circ} \mathrm{C}$ for $24 \mathrm{~h}$. Samples of the dried seeds were ground using a blender.

About $100 \mathrm{~g}$ of the well-crushed bergamot seeds were fed into a soxhlet extractor. Petroleum ether $\left(40-60^{\circ} \mathrm{C}\right)$ was used as extraction solvent. After extraction, which lasted about 10 hours, the solvent was removed by distillation under vacuum. Further residual solvent was eliminated by nitrogen flow.

After being weighed, the oil yields were calculated. This process was repeated for seeds from all three cultivars.

\section{Chemical and physical analysis}

Density and viscosity value of the oils were determined according to AOAC (2005).

\section{lodine value}

For each of the three oils, $0.2 \mathrm{~g}$ was weighed and introduced into a pyrex glass flask. The oil was dissolved in a mixture of cyclohexane/acetic acid $(30 \mathrm{~mL})$. Then, $20 \mathrm{~mL}$ of a Wijs solution was added. The flask was closed and stored away from the light. After one hour, 15\% KI (potassium iodide) solution $(10 \mathrm{~mL})$ and $50 \mathrm{~mL}$ of distilled water were added. A $0.1 \mathrm{~N}$ sodium thiosulphate was used to titrate the iodine liberated by the reaction. Starch solution was used as indicator (Consolidated text for olive oil analysis, Annex XVI Consleg 2003).

\section{Determination of free acidity}

Two grammes of each oils, was weighed accurately in a conical flask and dissolved in a mixture of diethyl ether and ethanol (1: 1) then three drops of phenolphthalein were added (Consleg 2003). The solution was titrated with 0.1 $\mathrm{N} \mathrm{NaOH}$ until it became pink (end point). Results were expressed as $\mathrm{g}$ of oleic acid / $100 \mathrm{~g}$ of bergamot seed oil.

\section{Determination of peroxide value}

The peroxide value was calculated according to the method described in the official gazette no. 1513/2003 of the EU.

\section{Fatty acid methyl esters analysis}

Methyl esters of fatty acids were prepared following to the Official EU Method (EEC 1991). The analysis was conducted by gas chromatography using a Fison Instrument 8000 GC with a split-splitless injector and a FID (Flame Ionization Detector). A Supelcowax TM-10 $30 \mathrm{~m} \times 0.53 \mathrm{~mm}, 0.20 \mu \mathrm{m}$ column was used. The carrier gas was helium with a flow rate of 0.75 bar. Auxiliary 
gases were air (1,5 bar) and hydrogen (1 bar). The column temperature was programmed as follows: Initially, $180^{\circ} \mathrm{C}$, rate of rise $5^{\circ} \mathrm{C} / \mathrm{min}$ up to $240^{\circ} \mathrm{C}$ then and then isotherm for $10 \mathrm{~min}$. The identification of the constituents was based on the comparison of their retention indices with those published data or with authentic compounds.

\section{Determination of sterols}

The Official EU Method (EEC 1991) was used to separate the sterol fraction using the TLC-GC technique to separate the sterol fraction. Silica gel plates were used $(20 \mathrm{x} 20 \mathrm{~cm} \times$ $0.25 \mathrm{~mm}$ ). The saturation of the chromatographic chamber was performed using a mixture of hexane/ ethyl ether with a ratio of 65:35; The run had a duration of $20 \mathrm{~min}$.

The gas chromatographic analyses were carried out using a Fisons Instruments (GC 8000) gas chromatograph, with a flame ionization detector (FID). The capillary column ( $25 \mathrm{~m} \times 0.32 \mathrm{~mm}$ i.d., film thickness $0.25 \mu \mathrm{m}$ ) coated with an SE54 stationary phase. Helium was the carrier gas at a pressure of 0.76 bar and chromatographic air at a pressure of $1.52 \mathrm{bar}$. The column temperature was programmed as follows: Initially, $260^{\circ} \mathrm{C}(15 \mathrm{~min})$, with an increase of $5{ }^{\circ} \mathrm{C}$ per min. until a $270{ }^{\circ} \mathrm{C}$ maintained for $20 \mathrm{~min}$. The injector and FID detector were at $280{ }^{\circ} \mathrm{C}$ and $300^{\circ} \mathrm{C}$ respectively.

\section{Statistical analysis}

Statistical analysis was carried out using SPSS version 17.0 for windows. One-way analysis of variance (ANOVA) was used to evaluate the influence of cultivar on sterol and fatty acid content. Any significant difference between all treatments at $\mathrm{P}<0.05$, was determined using Tukey's Test.

Mean and standard deviation was determined using Microsoft Excel.

\section{RESULTS AND DISCUSSION}

The seeds came from bergamot fruit picked on the same day and processed within 48 hours. This fact is important since the lipid fraction obtained from citrus fruit seeds varies according to the fruit's ripeness, as described by Saidani et al. (2011).

Table 1 shows the extraction time of the oil and the yield expressed as a percentage. The oil yield is between 34.18 $\%$ and $35.01 \%$, similar values are reported from Saidani et al. (2004).

The physico-chemical characteristics of the oils are shown in Table 2. The oils showed no significant $(\mathrm{P}>$ $0.05)$ variations regarding viscosity and density, which ranged from 0.07 to $0.07\left(10^{-1} \mathrm{~Pa} \bullet \mathrm{s}\right)$ and $0.91-0.92 \mathrm{~g} / \mathrm{cm}^{3}$, respectively. Density values are similar to those given by
Table 1: Extraction with petroleum ether

\begin{tabular}{lccl}
\hline Cultivar & $\begin{array}{c}\text { Time of } \\
\text { extraction }(\mathrm{h})\end{array}$ & Yield \% & $\begin{array}{l}\text { Physical state at } \\
\text { room temperature }\end{array}$ \\
\hline Castagnaro & 8 & 35.01 & Liquid \\
Fantastico & 8 & 34.18 & Liquid \\
Femminello & 8 & 33.91 & Liquid \\
\hline
\end{tabular}

Habib et al. (1986) and Abdel-Rahman (1980), for Egyptian citrus seed oils $\left(0.913-0.933 \mathrm{~g} / \mathrm{cm}^{3}\right)$.

The iodine value is important for oils, because a high value indicates a high level of unsaturation (Knothe, 2002). The iodine values were 103.21, 102.56 and 101.37 for Castagnaro, Fantastico and Femminello seed oils, respectively. The iodine values of Citrus bergamia indicate that they belong to the semi-drying group. The viscosity was $0.07(\mathrm{~Pa} . \mathrm{s})$ for the seed oils of all three cultivars.

The density of the oils is in relation to their degree of unsaturation: A higher unsaturation level indicates a higher density (Gunstone, 2004). The density of the bergamot seed oil in the present study was $0.91333 \mathrm{~g} / \mathrm{mL}$.

The acid values were $0.87,0.62$, and 0.80 for Castagnaro, Fantastico and Femminello seed oils, respectively. Similar values were found in citrus seed oils by El-adawy (1999). The peroxide values were $14.30,11.67$ and $12.38 \mathrm{meq} / \mathrm{O}_{2}$ $\mathrm{kg}$ oil, for Castagnaro, Fantastico and Femminello seed oils, respectively.

Table 3 gives the fatty acid composition in bergamot seed oil. The fatty acid methyl esters indicated showed the presence of the following fatty acids: Palmitic acid, stearic acid, oleic acid, linoleic acid, linolenic acid and arachidic acid. In all, six fatty acids were present, of which three were unsaturated. The major fatty acids in bergamot oil were oleic, linoleic, palmitic and linolenic which made up $95 \%$ of total fatty acids. The major fatty acid was oleic acid $(31.54 \%$ for Femminello, to $33.02 \%$ for Fantastico and $34.55 \%$ for Castagnaro seed oil).

The concentration of oleic acid found in the bergamot seeds is greater than found in seeds from other citrus fruits (El-Adawy et al., 1999; Anwar et al., 2008; Waheed et al., 2009 and Trandjiiska and Nguyen. 1989). The content of oleic acid in the oil is on average $33.03 \%$, whereas oil from citron, orange and mandarin seeds has an average oleic acid content of $22.5 \%, 26.00 \%$ and $24.89 \%$ respectively (Fig. 1). Furthermore the quantity of linolenic acid is also greater in bergamot seed oil compared to oil from citron, orange and mandarin. However, the quantity of linoleic acid in bergamot seed oil is less than quantity found oils from the other citrus seeds (El-Adawy et al., 1999) (Fig. 1). 
Sicari, et al.: Composition of bergamot oil seed

Table 2: Physicochemical quality parameters evaluated in the bergamot seed oil samples

\begin{tabular}{|c|c|c|c|c|c|}
\hline Cultivar & Density at $25^{\circ} \mathrm{C}\left(\mathrm{g} \mathrm{cm}^{-3}\right)$ & Viscosity $10^{-1} \mathrm{~Pa} \cdot \mathrm{s}$ & lodine value $\mathrm{mg} \mathrm{g}^{-1}$ oil & Acidity $\mathrm{g} / 100 \mathrm{~g}$ & Peroxide meq $\mathrm{O}_{2} \mathrm{~kg}^{-1}$ oil \\
\hline Castagnaro & $0.91 \pm 0.01^{a}$ & $0.07 \pm 0.00^{a}$ & $103.21 \pm 0.02^{a}$ & $0.87 \pm 0.11^{a}$ & $14,30 \pm 0.03^{a}$ \\
\hline Fantastico & $0.92 \pm 0.01^{\mathrm{a}}$ & $0.07 \pm 0.00^{\mathrm{a}}$ & $102.56 \pm 0.02^{b}$ & $0,62 \pm 0.06^{c}$ & $11.67 \pm 0.04^{c}$ \\
\hline Femminello & $0.91 \pm 0.01^{a}$ & $0.07 \pm 0.00^{a}$ & $101.37 \pm 0.03^{c}$ & $0,80 \pm 0.32^{b}$ & $12,38 \pm 0.20^{b}$ \\
\hline
\end{tabular}

Values are mean $\pm S D$ of three sample seed oils, analyzed in triplicate, different letters indicate significant differences. differences were evaluated by one-way analysis of variance (ANOVA) test completed with a multicomparison Tukey's test, ${ }^{* *} P<0.05$ compared with the positive control

Table 3: Fatty acid composition (\%) of bergamot seed oil

\begin{tabular}{lccc}
\hline Fatty acid & \multicolumn{3}{c}{ Cultivars } \\
\cline { 2 - 4 } & Fantastico & Castagnaro & Femminello \\
\hline $\begin{array}{l}\text { Palmitic } \\
\text { acid }\left(C_{16: 0}\right)\end{array}$ & $23.04 \pm 0.64^{\mathrm{a}}$ & $21.03 \pm 0.63^{\mathrm{c}}$ & $22.44 \pm 0.74^{\mathrm{b}}$ \\
$\begin{array}{l}\text { Stearic } \\
\text { acid }\left(C_{18: 0}\right)\end{array}$ & $3.62 \pm 0.21^{\mathrm{b}}$ & $3.87 \pm 0.04^{\mathrm{a}}$ & $3.09 \pm 0.01^{\mathrm{c}}$ \\
$\begin{array}{l}\text { Oleic } \\
\text { acid }\left(C_{18: 1}\right) n-9\end{array}$ & $33.02 \pm 1.47^{\mathrm{b}}$ & $34.55 \pm 1.03^{\mathrm{a}}$ & $31.54 \pm 1.56^{\mathrm{c}}$ \\
$\begin{array}{l}\text { Linoleic } \\
\text { acid }\left(C_{18: 2}\right) n-6\end{array}$ & $28.21 \pm 1.45^{\mathrm{b}}$ & $27.98 \pm 1.01^{\mathrm{c}}$ & $30.01 \pm 2.01^{\mathrm{b}}$ \\
$\begin{array}{l}\text { Linolenic } \\
\text { acid }\left(C_{18: 3}\right) n-3\end{array}$ & $11.22 \pm 1.21^{\mathrm{b}}$ & $10.41 \pm 0.95^{\mathrm{c}}$ & $11.08 \pm 0.75^{\mathrm{b}}$ \\
$\begin{array}{l}\text { Arachidic } \\
\text { acid }\left(C_{20: 0}\right)\end{array}$ & $0.44 \pm 0.01^{\mathrm{ab}}$ & $0.41 \pm 0.02^{\mathrm{a}}$ & $0.38 \pm 0.03^{\mathrm{b}}$ \\
$\begin{array}{l}\text { Total fatty acid } \\
\text { Total } \\
\text { unsatured } \\
\text { fatty acid }\end{array}$ & 99.55 & 98.25 & 98.54 \\
$\begin{array}{l}\text { Total satured } \\
\text { fatty acid }\end{array}$ & 27.10 & 72.94 & 72.63 \\
$\begin{array}{l}\text { Total essential } \\
\text { fatty acid }\end{array}$ & 39.43 & 25.31 & 25.91 \\
\hline
\end{tabular}

Values are mean $\pm S D$ of three sample seed oils, analyzed in triplicate, different letters indicate significant differences, differences were evaluated by one-way analysis of variance (ANOVA) test completed with a multicomparison Tukey's test, ${ }^{\star \star} P<0.05$ compared with the positive control

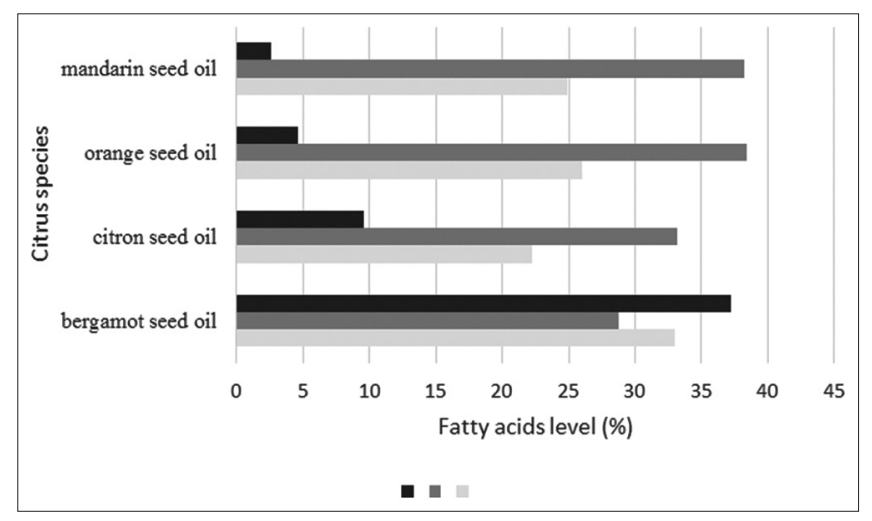

Fig 1. Comparison of the oleic, linoleic and linolenic acid, of bergamot, orange, citron and tangerine oil seeds. The content of the fatty acids present in the oil of bergamot are the average value of the concentration of the three cultivars. While the content of the same in the other citrus fruits are those obtained by El-Adawy et al. (1999).

In edible oils, the ratio of unsaturated to saturated fatty acids plays an important role in human nutrition. The total mean of unsaturated fatty acids in bergamot seed oil was $72.94 \%$ of total fatty acids. Fatty acid composition of bergamot seed oil varies only slightly between cultivars.

The concentration of bergamot seed oil fatty acids shows that food use of this oil may have beneficial effects on consumer health. In fact, the ratio of unsaturated and saturated fatty acids can reduce the risk of heart diseases (Bhatnagar and Durrington 2003; Von Schacky 2003). In fact, high levels of saturated fatty acids result in an increase of the LDL (low density lipoprotein) (Holub 2002; Nilsen et al., 2001; Bhatnagar and Durrington, 2003).

Of the saturated fatty acids, palmitic acid ranged between $23.04 \%$ and $21.03 \%$ and stearic acid ranged between 3.09 and $3.87 \%$.

The palmitic acid content is lower than that found in oil from grapefruit, orange and mandarin seeds (El-Adawy et al., 1999; Anwar et al., 2008). While arachidic acid ranged between $0.38 \%$ and $0.44 \%$, which is similar to earlier investigations into various citrus seed oils (El-Adawy et al., 1999; Anwar et al., 2008). The fatty acid profile of bergamot seed oil (Table 3) shows a slightly higher percentage of unsaturated fatty acids compared to saturated fatty acids which is similar to earlier investigations into various citrus seed oils (Anwar et al., 2008).

The ratio between saturated and unsaturated fatty acids was 1:2.67; 1:2.88 and 1:2.80 in Fantastico, Castagnaro and Femminello respectively. These results are slightly below than those found by Moussa (1990).

The content of linoleic acid is lower in bergamot seed oils than in other citrus seed oils. Other authors have found that the of linoleic acid content in orange, lemon and grapefruit oils may be $40 \%$ of the total fatty acids (Anwar 2008; Spiller et al., 1991).

Linolenic acid can reach 10\% of total acids found in bergamot seed oils. This agrees with its high presence in other citrus seed oils (Anwar 2008).

The total essential fatty acid content (linoleic and linolenic acids), which have positive health benefits, ranged between 38.39-41.09\% (Table 3) which concord with those reported for Egyptian citrus seed oils (40.8-43.0\%) (Anwar et al., 
2008). Fig. 1 gives a comparison with other citrus essential fatty acids.

Table 4 shows the composition of the sterol fraction. The following sterols were found in bergamot seed oil: Cholesterol, 2,4-methylencholesterol, campersterol, stigmasterol, $\beta$-sitosterol and $\Delta^{5}$-avenasterol.

In all bergamot seed oils analized, the steol present in the greatest quantity was $\beta$-sitosterol, which agrees with earlier investigations in to other varieties of citron seed oil (Lazos and Servos, 1988; Matthausa and Özcan, 2012). The oils from the three different bergamot cultivars showed very similar amount of $\beta$-sitosterol: Between 79.67 and $81.68 \%$. The quantity of $\beta$-sitosterol is slightly greater than that found in other citrus seed oils. In those oils analized by Matthausa and Özcan (2012), the content of $\beta$-sitosterol was $71.7 \%$ in orange seed oil (Citrus aurantifolia), $75.1 \%$ in grapefruit seed oil (Citrus paradisi) and 74.9\% in lemon seed oil (Citrus lemon) (Fig. 2).

Among other sterols identified, after $\beta$-sitosterol, campsterol is present in the greatest quantity. The highest percentage, of $12.4 \%$ was found in the Fantastico cultivar, whereas Femminello and Castagnaro showed percentages of 11.52 and $10.87 \%$ respectively. The quantity of campesterol present in these oils is very similar to that found in other citrus seed oil (Matthausa and Özcan, 2012), except for oil from Citus sinensis which has a percentage of $8.4 \%$. The amount of 2,4-methylencholesterol found in bergamot seed oil was 0.62, 0.55 and $0.48 \%$ for Fantastico, Femminello and Castagnaro cultivars respectively. Compared to oils from other citrus fruit, this sterol is present in greater quantity ((Matthausa and Özcan, 2012). The concentration of the other sterols identified (stigmasterol, $\Delta^{5}$-avenasterol and cholesterol) is very similar in oil from all other cultivars in the study, as can be seen in the Table 4 .

In bergamot seed oil, $\beta$-sitosterol is present in a higher percentage than in oils derived from other seeds.

\section{CONCLUSIONS}

Citrus seed oils are a source of comestible oil appropriate for human consumption. The results indicate that the oils extracted from bergamot seeds of all three cultivars are valuable source of essential fatty acids.

The viscosity, density and iodine value do not show significant differences between the three cultivars. The oil had a good oxidative stability as shown by acidity and peroxide value.

It is potentially suitable for human composition although preconditions are necessary for food use, due to its high

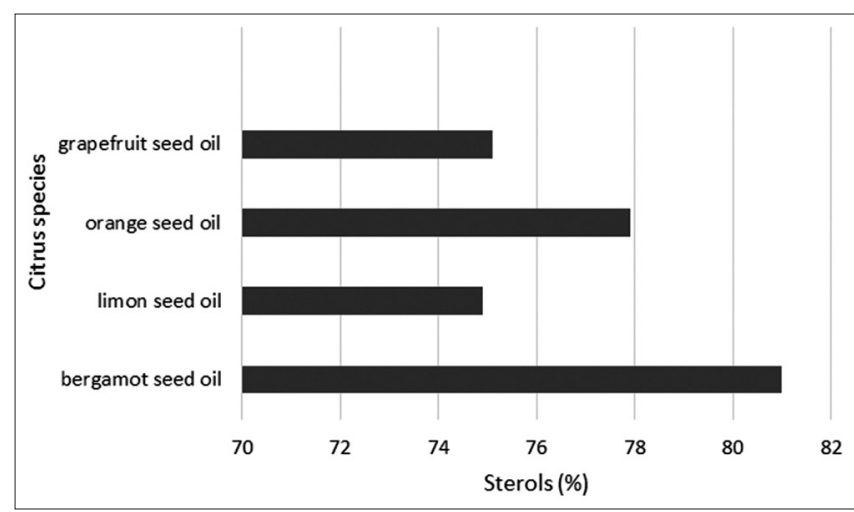

Fig 2. Comparison between the $\beta$-sitosterol content of bergamot, lemon, orange and grapefruit oil seeds. The $\beta$-sitosterol content in bergamot oil seed is the average of that contained in the three cultivars object of the experimentation. While the content of the same in the other citrus fruits is that reported by Matthausa and Özcanb, 2012).

Table 4: Sterol composition (\%) of bergamot seed oil

\begin{tabular}{lccc|}
\hline Sterol & \multicolumn{3}{c|}{ Cultivars } \\
\cline { 2 - 4 } & Fantastico & Castagnaro & Femminello \\
\hline Colesterol & $0.77 \pm 0.16^{\mathrm{a}}$ & $0.68 \pm 0.01^{\mathrm{b}}$ & $0.71 \pm 0.22^{\mathrm{ab}}$ \\
2,4-methylencolesterol & $0.62 \pm 0.13^{\mathrm{a}}$ & $0.48 \pm 0.02^{\mathrm{b}}$ & $0.55 \pm 0.01^{\mathrm{ab}}$ \\
Campesterol & $12.04 \pm 1.13^{\mathrm{a}}$ & $10.87 \pm 0.12^{\mathrm{c}}$ & $11.52 \pm 1.83^{\mathrm{b}}$ \\
Stigmasterol & $4.53 \pm 0.22^{\mathrm{a}}$ & $4.32 \pm 0.04^{\mathrm{b}}$ & $4.01 \pm 0.01^{\mathrm{c}}$ \\
$\beta$-sitosterol & $79.67 \pm 3.27^{\mathrm{c}}$ & $81.68 \pm 4.06^{\mathrm{a}}$ & $81.60 \pm 5.30^{\mathrm{a}}$ \\
$\Delta^{5}$-avenasterol & $2.04 \pm 0.16^{\mathrm{ab}}$ & $1.97 \pm 0.11^{\mathrm{b}}$ & $2.16 \pm 0.14^{\mathrm{a}}$ \\
& $* *$ & $* *$ & $* *$ \\
\hline
\end{tabular}

Values are mean \pm SD of three sample seed oils, analyzed in triplicate, different letters indicate significant differences, differences were evaluated by one-way analysis of variance (ANOVA) test completed with a multicomparison Tukey's test, ${ }^{* *} \mathrm{P}<0.05$ compared with the positive control

oxidability. Composition is dominated by $\beta$-sitosterol, as are many other vegetable oils.

The seeds of the bergamot fruit, which are currently considered a waste material, may not only be a reliable source of edible oil, but since it is a siccative oil it could also have industrial uses.

\section{Author's contributions}

The experiments were conducted, and data analyzed by Teresa M. Pellicanò. Analyzes were conducted by Francesco Messina. The study was designed, results interpreted, and manuscript drafted by Vincenzo Sicari.

\section{REFERENCES}

Abdel-Rahman, A. Y. 1980. A study on some Egyption Citrus seed oils. Grasas Aceites. 31: 331-333.

Adiletta, G., A. Memoli, D. Albanese, A. Crescitelli and M. Di Matteo. 2015. Lutein extraction from tomato peels and its evaluation of heat stability. ISHS Acta Horticulturae 1081: XIII International Symposium on Processing Tomato.

Anwar, F., R. Naseer, M. I. Bhanger, S. Ashraf, F. N. Talpur and F. A. Aladedunye. 2008. Physico-chemical characteristics of 
Citrus seeds and seed oils from Pakistan. J. Am. Oil Chem. Soc. 85: 321-330.

AOAC. (2005). Official Methods of Analysis, $18^{\text {th }}$ ed. Association of Official Analytical Chemists, Washington, DC, USA, 969.33, 996.06 and 970.51.

Bhatia, V. K., A. Chaudhry, G. A. Sivasankaran, R. P. Bishi and M. Kashyap. 1990. Modification of jojoba oil for lubricant formulations. J. Am. Oil Chem. Soc. 67: 1-7.

Bhatnagar, D. and P. N. Durrington. 2003. Omega-3 fatty acids: Their role in the prevention and treatment of atherosclerosis related risk factors and complications. Int. J. Clin. Pract. 57: 305-314.

Consolidated Text, Consleg: 1991, 2568, 01/11/2003, on the Characteristics of Olive Oil and Olive-Residue Oil and on the Relevant Methods of Analysis.

Danby, S., T. Al-Enezi, A. Sultan, T. Lavender, J. Chittock, K. Brown and M. Cork. 2013. Effect of olive and sunflower seed oil on the adult skin barrier: Implications for neonatal skin care. Pediatr. Dermatol. 30: 42-50.

Dugo, G., G. Lamonica, A. Cotroneo, A. Trozzi, F. Crispo, F. G. Licandro and D. Gioffrè. 1987. SSEA, Reggio Calabria. Monografie Oli Essenziali e Derivati Agrumari.

EEC Commission Regulation No. 2568/91. Official Journal No. L 248 September 5, 1991.

El-Adawy, T. A., E. H. Rahman, A. A. El-Bedawy and M. Gafar. 1999. Properties of some Citrus seeds. Part evaluation as a new source of protein and oil. Nahrung. 43: 385-391.

Foidl, N., G. Foidl, M. Sanchez, M. Mittelbach and S. Hackel. 1996. Jatropha curcas L. as a source of production of biofuel in Nicaragua. Bioresour. Technol. 58: 77-82.

French, R. B. 1962. Analyses of pecan, peanut and other oils by gas-liquid chromatography and ultra-violet spectrophotometry. J. Am. Oil Chem. Soc. 39: 176-178.

Giuffrè, A. M., C. Zappia, M. Capocasale, V. Sicari, T. M. Pellicanò and M. Poiana. 2015. Caratteristiche fisico-chimiche dell'olio di semi di pomodoro per uso alimentare. Poster. CISETA. 2015. 12 Congresso Italiano di Scienza e Tecnologia Degli Alimenti.

Giuffrè, A. M., M. Capocasale, C. Zappia, V. Sicari, T. M. Pellicanò, G. Pansera and M. Poiana. 2015. Tomato seed oil for biodiesel production. Eur. J. Lipid Sci. Technol. 117: 1438-7697.

Giuffrè, A. M., S. Tellah, M. Capocasale, C. Zappia, M. Latati, M. Badiani and S. M. Ounane. 2016. Seed oil from ten Algerian peanut landraces for edible use and biodiesel production. J. Oleo Sci. 65: 9-20.

Giuffrè, A. M., V. Sicari, M. Capocasale, C. Zappia, T. M. Pellicanò and M. Poiana. 2015. Physico-chemical properties of tomato seed oil (Solanum lycopersicum L.) for biodiesel production. Acta Hortic. 1081: 237-244.

Gültekina, Ö., M. M. Özcan and F. Al-Juhaimi. 2016. Some physicochemical properties, fatty acid composition, and tocopherol contents of Citrus seed oils. La rivista italiana delle sostanze grasse - XCIII - Gennaio/Marzo; 2016.

Gunstone, F. D. 2004. Rapeseed and Canola Oil: Production, Processing, Properties and Uses, Blackwell Publishing Ltd., London.

Habib, M. A., M. A. Hammam, A. A. Sakr and Y. A. Ashoush. 1986.
Chemical evaluation of Egyptian Citrus seeds as potential sources of vegetable oils. J. Am. Oil Chem. Soc. 63: 1192-1196.

Holub, B. J. 2002. Clinical nutrition: 4. Omega-3 fatty acids in cardiovascular care. Can. Med. Assoc. J. 166: 608-615.

Knothe, G. 2006. Analyzing biodiesel: Standards and other methods. J. Am. Oil Chem. Soc. 83: 823-833.

Lazos, E. S. and D. C. Servos. 1988. Nutritional and chemical characteristics of orange seed oil. Grasas Aceites. 39: 232-234.

Mahmud, S., J. M. Akhgtar and A. Q. Ather. 2006. Lipid studies of Citrus seeds. Pak. J. Sci. Ind. Res. 45: 27--30.

Matthausa, B. and M. M. Özcanb. 2012. Chemical evaluation of Citrus seeds, an agro-industrial waste as a new potential source of vegetable oils. Grasas Aceites. 63: 313-320.

Moussa, S. H. 1990. Utilization of some agricultural industries wastes. $\mathrm{Ph}$. D. Thesis, Faculty of Agriculture, Minufiya University Shibin El-Kom, Egypt.

Nilsen, D. W., G. Albrektsen, K. Landmark, S. Moen, T. Aarsland and L. Woie. 2001. Effects of a high-dose concentrate of n-3 fatty acids or corn oil introduced early after an acute myocardial infarction on serum triacylglycerol and HDL cholesterol. Am. J. Clin. Nutr. 74: 50-56.

Poiana, M., E. Reverchon, V. Sicari, B. Mincione and F. Crispo. 1994. Supercritical carbon dioxide extraction of bergamot oil bergapten content in the extracts. Int. J. Food Sci. 4: 459-466.

Ramadan, M. F. and J. T. Morsel. 2002. Direct isocratic normal-phase HPLC assay of fat-soluble vitamins and b-carotene in oilseeds. Eur. Food Res. Technol. 214: 521-527.

Rewolinski, C. 1985. Sunflower oil diesel fuel: Lubrication system contamination. J. Am. Oil Chem. Soc. 62: 1120-1124.

Ricci, H. and P. Rovesti. 1979. Impieghi in cosmesi dell'olio essenziale di bergamotto. EPPOS. 61: 18-19.

Ristic, V. and G. Ristic. 2003: Role and importance of dietary polyunsaturated fatty acids in the prevention and therapy of atherosclerosis. Med. Pregl. 56: 50-53.

Saidani, M., W. Dhifi and B. Marzouk. 2004. Lipid evaluation of some Tunisian citrus seeds. J. Lipid Res. 11: 242-250.

Saidani, T. M., I. Moulehi, I. Ouerghemmi, H. Mejri, W. A. Wannes, G. H. H. Zemni, F. Limam and B. Marzouk. 2011. Changes in lipid composition and antioxidant capacity of bitter orange (Citrus aurantium. L) and Mandarin (Citrus reticulata. Blanco) oilseeds on different stages of maturity. J. Am. Oil Chem. Soc. 88: 961-966.

Sicari, V. and M. Poiana. 2016. Recovery of bergamot seed oil by supercritical carbon dioxide extraction and comparison with traditional solvent extraction. J. Food Process Eng.

Spiller, G.A. 1991. The Mediterranean diets in health and disease. Clin. Nutr. 51: 491-501.

Trandjiiska, R. and H. Nguyen. 1989. Triglyceride composition of seed oils from Vietnames Citrus fruits. Riv. Ital. Sostanze. Grasse. 66: 99-100.

Von Schacky, C. 2003. The role of omega-3 fatty acids in cardiovascular disease. Curr. Atheroscler. Rep. 5: 139-145.

Waheed, A., S. Mahmud, M. Saleem and T. Ahmad. 2009. Fatty acid composition of neutral lipid: classes of citrus seed oil. J. Saudi Chem. Soc. 13: 269-272. 